\title{
Comparative Analysis of China Light-duty Vehicle Test cycle for Passenger Car and Other Typical Driving Cycles
}

\author{
Yu Liu ${ }^{1,2^{*}}$, Yongkai Liang ${ }^{1,2}$, Hanzhengnan $\mathrm{Yu}^{1,2}$, Xiaopan $\mathrm{An}^{1,2}$, and Jingyuan $\mathrm{Li}^{1,2}$ \\ ${ }^{1}$ China Automotive Technology and Research Center Co., Ltd., Tianjin, China \\ ${ }^{2}$ CATARC Automotive Test Center (Tianjin) Co., Ltd.
}

\begin{abstract}
In 2019, China issued the first national standard for vehicle driving cycle, in which China lightduty vehicle test cycle for passenger car (CLTC-P) is the driving cycle for light-duty passenger cars. CLTC$\mathrm{P}$ is of great significance to the development of China's automobile industry, and has a great impact on the development and calibration of vehicles of automobile enterprises. In this paper, firstly, the driving characteristics of CLTC-P are analyzed systematically. Then it is compared with the third-party navigation big data to prove the rationality and effectiveness. Finally, CLTC-P is compared with other legal cycles in terms of time, distance, speed, and acceleration characteristics. The result shows that by comparing the characteristics of CLTC-P with other typical cycles and the GIS weighted results, the CLTC-P is more in line with Chinese reality and is significantly different from other typical cycles.
\end{abstract}

\section{Introduction}

Automotive test cycles are an important common basic technology in the automotive industry, and are the basis for energy consumption, emission test methods and limits standards [1-2]. At the beginning of last century, the direct adoption of New European Driving Cycle (NEDC) for the certification of the energy consumption and emissions of automotive has effectively promoted the development of automotive energy saving and emission reduction technologies. However, with the rapid growth of vehicle population and the continuous changes in road structure, real driving condition of passenger cars in China has undergone great changes [3-5]. Governments, enterprises and the public are increasingly discovering that the deviation of the actual fuel consumption of the cars calibrated based on NEDC with the certification results is increasing, which affects the credibility of the government. In addition, relevant research indicates that NEDC is not feasible to evaluate the practical application effects of energy-saving technologies such as idle start and stop and brake energy recovery.

Based on the above background, the Ministry of Industry and Information Technology (MIIT) of China set up a project of Research and Development of China Automotive Test Cycle (CATC) in 2015, and entrusted CATARC to take the lead in organizing the auto industry to complete it.

After 3 years of research, the CATC Program has established a data collection fleet of 5,048 vehicles in 41 typical cities across the country, and collected actual driving data of more than 55 million kilometers. In addition, the low frequency traffic volume data of geographic information system (GIS) was innovatively introduced, and solved the problem that the macroscopic weight of driving cycle is greatly influenced by subjective choice. Finally, A total of 8 test cycles for light and heavy-duty vehicles is established.

This article will conduct a systematic analysis of the China Light-duty Passenger car Test Cycle (CLTC-P), and compare it with the third-party big data and the typical driving cycles, such as the Federal Test Procedure (FTP-75) in United States and the NEDC and worldwide harmonized light vehicles test cycle (WLTC) in Euro in detail [6-8].

\section{Analysis of characteristics of CLTC-P}

The CLTC-P contains a total of 11 short trips (including 7 short trips in the low-speed phase, 3 short trips in the medium-speed phase, and 1 short trip in the high-speed phase) and 12 idle segments, with a total duration of 1800 seconds. The speed profile of the CLTC-P driving cycle is given in Figure 1. The average speed is $28.96 \mathrm{~km} / \mathrm{h}$, the maximum speed is $114.0 \mathrm{~km} / \mathrm{h}$, and the idle ratio is $22.11 \%$. The specific characteristics are shown in Table 1.

Table 1. The characteristics of CLTC-P

\begin{tabular}{|l|l|l|l|l|}
\hline \multicolumn{1}{|c|}{ Parameter } & $\begin{array}{l}\text { CLTC } \\
\text {-P }\end{array}$ & $\begin{array}{l}\text { CLTC } \\
\text {-P1 }\end{array}$ & $\begin{array}{l}\text { CLTC } \\
\text {-P2 }\end{array}$ & $\begin{array}{l}\text { CLTC } \\
\text {-P3 }\end{array}$ \\
\hline Duration(s) & 1800 & 674 & 693 & 433 \\
\hline Distance $(\mathrm{km})$ & 14.48 & 2.45 & 5.91 & 6.12 \\
\hline Maximum speed $(\mathrm{km} / \mathrm{h})$ & 114.00 & 48.10 & 71.20 & 114.00 \\
\hline $\begin{array}{l}\text { Maximum } \\
\text { acceleration }\left(\mathrm{m} / \mathrm{s}^{2}\right)\end{array}$ & 1.47 & 1.47 & 1.44 & 1.06 \\
\hline $\begin{array}{l}\text { Maximum deceleration } \\
\left(\mathrm{m} / \mathrm{s}^{2}\right)\end{array}$ & -1.47 & -1.42 & -1.47 & -1.46 \\
\hline
\end{tabular}




\begin{tabular}{|l|l|l|l|l|}
\hline Average speed $(\mathrm{km} / \mathrm{h})$ & 28.96 & 13.09 & 30.68 & 50.90 \\
\hline $\begin{array}{l}\text { Running average speed } \\
(\mathrm{km} / \mathrm{h})\end{array}$ & 37.18 & 20.19 & 38.24 & 53.89 \\
\hline $\begin{array}{l}\text { Average acceleration } \\
\left(\mathrm{m} / \mathrm{s}^{2}\right)\end{array}$ & 0.45 & 0.42 & 0.46 & 0.46 \\
\hline $\begin{array}{l}\text { Average } \\
\left.\text { deceleration(m/s } \mathrm{s}^{2}\right)\end{array}$ & -0.49 & -0.45 & -0.50 & -0.54 \\
\hline $\begin{array}{l}\text { Relative positive } \\
\text { acceleration(m/s })\end{array}$ & 0.17 & 0.14 & 0.16 & 0.18 \\
\hline Acceleration ratio (\%) & 28.61 & 22.26 & 30.45 & 35.57 \\
\hline Deceleration ratio (\%) & 26.44 & 21.51 & 28.43 & 30.95 \\
\hline Cruise ratio $(\%)$ & 22.83 & 21.07 & 21.36 & 27.94 \\
\hline Idle ratio $(\%)$ & 22.11 & 35.16 & 19.77 & 5.54 \\
\hline
\end{tabular}

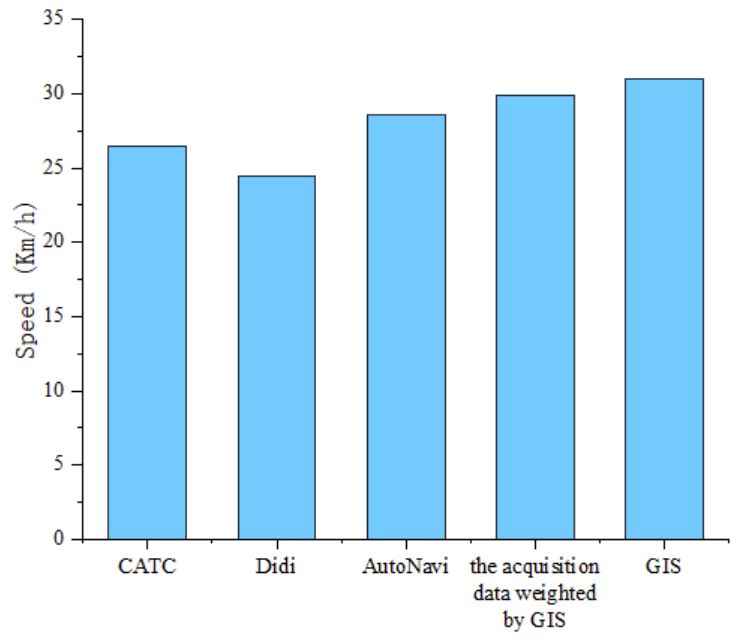

Fig. 2. The average speed of third-party navigation big data

From Figure 2, it can be found that CLTC-P is relatively close to the acquisition data and the acquisition data weighted by GIS, and is in the middle, reflecting that CLTC-P is in line with Chinese reality.

\section{Comparison of CLTC-P with other typical driving cycles}

Fig. 1. The speed profile of the CLTC-P driving cycle

\section{Comparison of CLTC-P and third-party navigation big data}

The research adopts sampling data from professional traffic data analysis and information release platforms in general traffic guidance and travel planning.

Didi Platform: The Didi platform is a vehicle operation management platform developed by Beijing Xiaoju Technology Co., Ltd. and funded by Uber and Tencent. There are more than 10 million registered vehicles, more than 1.5 billion trip orders, and over 12.8 billion $\mathrm{km}$ of data. The sampling period is 1 minute.

AutoNavi Transportation Platform: The leading domestic digital map, travel guidance plan and traffic status data release platform developed by AutoNavi, the data sampling period is 1 minute.

The Baidu GIS: A geographic information system platform developed by Baidu. The platform provides data support for Baidu's travel guidance and traffic status discrimination, and the sampling period is 5 minutes.

The weighted speed is calculated by weighting the collected data by GIS weight, which is obtained by calculating the traffic volume/total traffic volume of each city through GIS data.

The weighted speed is calculated by weighting the collected data by GIS weight factor, which is obtained by calculating the traffic volume/total traffic volume of each city through GIS data.

In this section, the operation characteristics of the CLTC$\mathrm{P}$ are compared with several typical driving cycles, such as the FTP-75 in United States and the NEDC and WLTC in Euro.

\subsection{Comparison of duration characteristics}

The duration characteristics of several driving cycles are shown in Table 2 and Figure 3-4. Compared with NEDC steady cycle, WLTC and CLTC-P are transient cycles. All short trips and idle segments are synthesized according to the actual operation data. From the comparison of duration, the transient cycle is longer (such as FTP-75, WLTC, CLTC-P); the modal driving cycle duration is relatively short (such as NEDC). NEDC duration is only 1180 seconds.

Table 2. Duration characteristic distribution of different cycles

\begin{tabular}{|l|l|l|l|l|l|l|}
\hline & NEDC & $\begin{array}{l}\text { FTP- } \\
75\end{array}$ & WLTC & $\begin{array}{l}\text { CLTC- } \\
\text { PEDC }\end{array}$ & $\begin{array}{l}\text { NEDC } \\
2\end{array}$ \\
\hline Duration(s) & 1180 & 1874 & 1800 & 1800 & 780 & 400 \\
\hline $\begin{array}{l}\text { Acceleration } \\
\text { duration(s) }\end{array}$ & 274 & 584 & 557 & 515 & 168 & 106 \\
\hline Ratio (\%) & 23.22 & 31.16 & 30.94 & 28.61 & 21.54 & 26.5 \\
\hline $\begin{array}{l}\text { Deceleration } \\
\text { duration(s) }\end{array}$ & 196 & 507 & 514 & 476 & 152 & 44 \\
\hline Ratio (\%) & 16.61 & 27.05 & 28.56 & 26.44 & 19.49 & 11 \\
\hline Cruise duration(s) & 443 & 463 & 501 & 411 & 232 & 211 \\
\hline Ratio (\%) & 37.54 & 24.71 & 27.83 & 22.83 & 29.74 & 52.75 \\
\hline Idle duration(s) & 267 & 320 & 228 & 398 & 228 & 39 \\
\hline Ratio (\%) & 22.63 & 17.08 & 12.67 & 22.11 & 29.23 & 9.75 \\
\hline
\end{tabular}




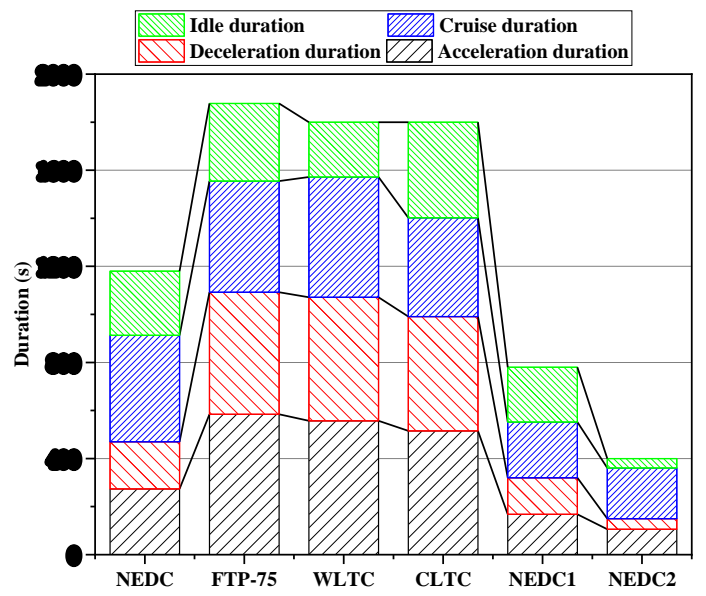

Fig. 3. Typical driving cycles duration distribution

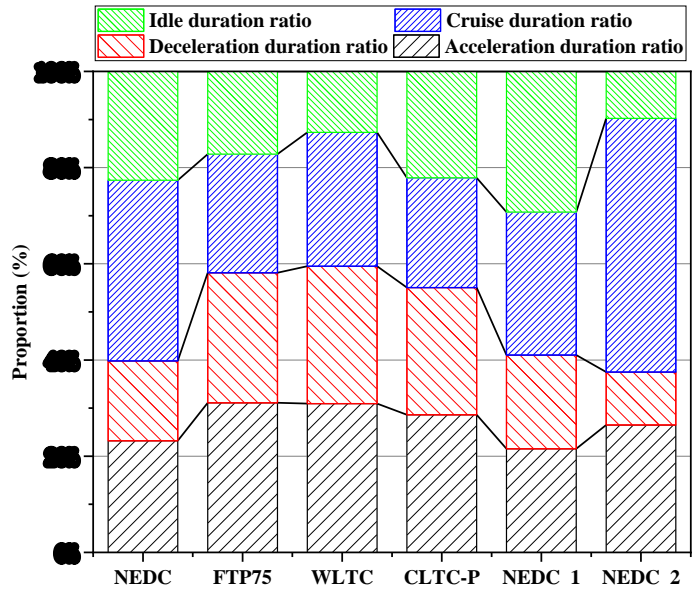

Fig. 4. Comparison of acceleration ratio, deceleration ratio, cruise ratio and idle ratio of typical cycles

From the distribution of duration ratio, the idle ratio of high-speed phase (such as NEDC-2) is significantly lower than that of corresponding urban cycle (such as FTP-75, NEDC-1), which is consistent with actual traffic conditions. Judging from the comparison of urban cycle between different countries, the idle ratio of FTP-75 in the United States in urban driving cycle and WLTC are the lowest, reflecting good traffic conditions. The NEDC1 and CLTC-P have higher idle ratio, representing relative congested traffic condition.

\subsection{Comparison of distance characteristics of typical driving cycles}

The distance characteristics of typical driving cycles are shown in Table 3, Figure5-6. From the comparison of distance of driving cycle, the distance of transient cycle synthesized according to the collected data of actual vehicles is longer (such as CLTC-P, WLTC, FTP-75). The distance of modal driving cycle is relatively short (such as NEDC). WLTC has the longest distance, $23.21 \mathrm{~km}$; the distance of NEDC is the shortest, only $11.03 \mathrm{~km}$.
Table 3. Distance characteristics of typical cycle

\begin{tabular}{|l|l|l|l|l|l|l|}
\hline & NEDC & FTP-75 & WLTC & $\begin{array}{l}\text { CLTC } \\
\text {-P }\end{array}$ & NEDC1 & NEDC2 \\
\hline Distance & 11.03 & 17.68 & 23.21 & 14.48 & 4.07 & 6.96 \\
\hline $\begin{array}{l}\text { Acceleration } \\
\text { distance }\end{array}$ & 3.04 & 6.03 & 7.2 & 5.2 & 1 & 2.04 \\
\hline Ratio (\%) & 27.55 & 34.12 & 31.04 & 35.91 & 24.56 & 29.31 \\
\hline $\begin{array}{l}\text { Deceleration } \\
\text { distance }\end{array}$ & 1.74 & 5.19 & 6.41 & 4.75 & 0.91 & 0.83 \\
\hline Ratio (\%) & 15.74 & 29.36 & 27.61 & 32.78 & 22.35 & 11.86 \\
\hline $\begin{array}{l}\text { Cruise } \\
\text { distance }\end{array}$ & 6.25 & 6.46 & 9.6 & 4.53 & 2.16 & 4.09 \\
\hline Ratio (\%) & 56.71 & 36.52 & 41.35 & 31.31 & 53.09 & 58.83 \\
\hline
\end{tabular}

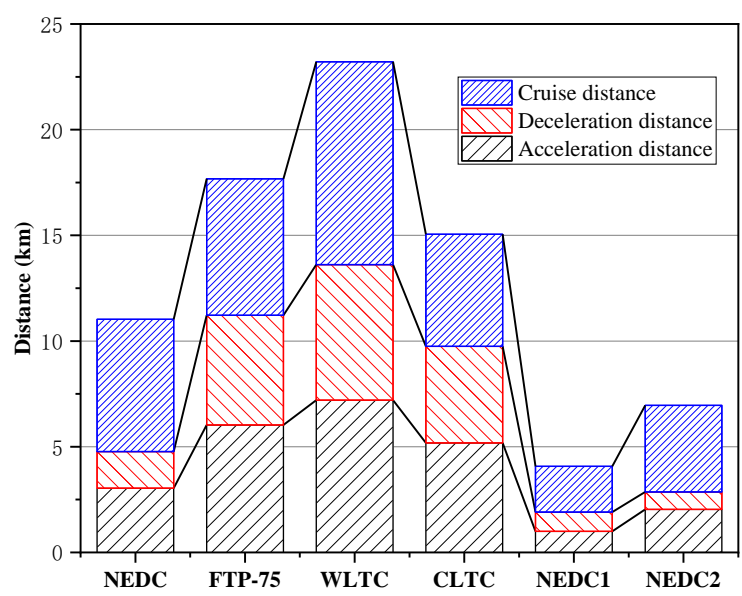

Fig. 5. Distance distribution of typical driving cycles

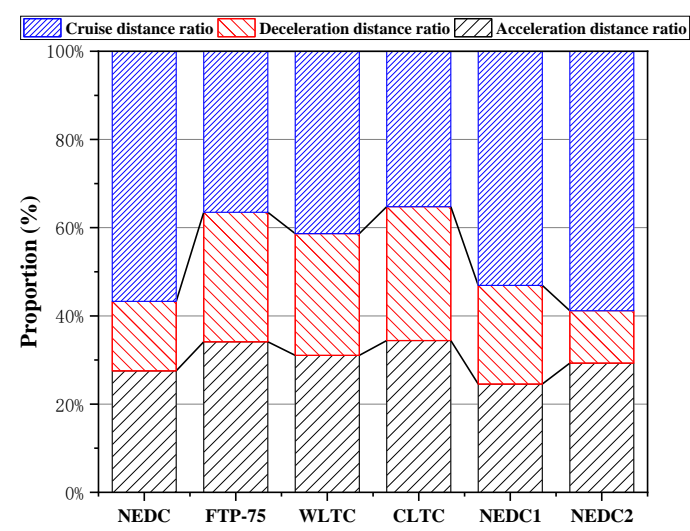

Fig. 6. Distance ratio distribution of typical driving cycles

From the perspective of distance distribution, the distance distribution of acceleration, deceleration and cruise in different driving cycles are quite different; the distance distribution of urban cycle (or basic cycle) and high-speed phase are also different. The reason is that the distance is simultaneously affected by time and speed, which is a comprehensive reflection of the product of the two. At present, the NEDC is adopted in Chinese lightduty vehicle as energy consumption, emission test methods and limits standards. NEDC-1(urban) and NEDC-2(extra-urban) distance are $4.05 \mathrm{~km}$ and $6.95 \mathrm{~km}$ 
respectively, and the ratio is $37: 63$. This is inconsistent with the driving conditions of most Chinese vehicles. Moreover, the NEDC as a modal driving cycle is too simple, and it can no longer fit the current emission and energy consumption evaluation needs of various types of vehicles and various driving cycles.

\subsection{Comparison of speed characteristics}

Table 4 and Figure 7 show the comparison of speed characteristics of driving cycles. In terms of idle ratio (speed less than $0.5 \mathrm{~km} / \mathrm{h}$ ), the idle ratio of CLTC-P is significantly higher than that of WLTC, and NEDC is slightly higher than CLTC-P. From the perspective of the maximum speed, the WLTC is the highest at $131.3 \mathrm{~km} / \mathrm{h}$; the CLTC-P and NEDC-2 are $114 \mathrm{~km} / \mathrm{h}$ and $120 \mathrm{~km} / \mathrm{h}$ respectively. The average speed of WLTC reached $46.42 \mathrm{~km} / \mathrm{h}$, which is much higher than CLTC-P. In addition, the average speed of FTP-75 and NEDC is also higher than that of CLTC-P, reflecting from the side that the traffic conditions in Euro and American cities are better, which is consistent with the conclusion drawn from the analysis of duration characteristics. From the perspective of speed distribution, NEDC speed phase distribution has large fluctuations and does not conform to the actual operation regular pattern. This is also an inherent defect of steady cycle.

The division of speed phase under different driving cycle is also different; NEDC covers different road types (urban and extra-urban), and the maximum speed in urban is $50 \mathrm{~km} / \mathrm{h}$; CLTC-P is divided into different speed phases (low, middle and High) with threshold speed values of $60 \mathrm{~km} / \mathrm{h}, 80 \mathrm{~km} / \mathrm{h}$. WLTC includes four speed phases(low, middle, high and Extra-high). According to the actual distribution of operating conditions in China, the vehicles mainly operate in low and medium speed phase, and the proportion of high-speed phase is relatively low; while the proportion of high speed and extra-high speed phase in WLTC is very high, and its maximum speed is $131.31 \mathrm{~km} / \mathrm{h}, 5 \%$ of the cycle points have exceeded the vehicle speed limit $(120 \mathrm{~km} / \mathrm{h})$ in our country.

Table 4. Comparison of the speed characteristics

\begin{tabular}{|l|l|l|l|l|l|l|}
\hline & NEDC & $\begin{array}{l}\text { FTP- } \\
75\end{array}$ & WLTC & $\begin{array}{l}\text { CLTC- } \\
\mathrm{P}\end{array}$ & $\begin{array}{l}\text { NEDC } \\
1\end{array}$ & $\begin{array}{l}\text { NEDC } \\
2\end{array}$ \\
\hline $\begin{array}{l}\text { Maximum speed } \\
\mathrm{km} / \mathrm{h})\end{array}$ & 120 & 90.16 & 131.3 & 114 & 50 & 120 \\
\hline $\begin{array}{l}\text { Average speed } \\
(\mathrm{km} / \mathrm{h})\end{array}$ & 33.64 & 33.89 & 46.42 & 28.96 & 18.8 & 62.6 \\
\hline $\begin{array}{l}\text { Running average } \\
\text { speed }(\mathrm{km} / \mathrm{h})\end{array}$ & 43.48 & 40.93 & 53.15 & 37.18 & 26.56 & 69.36 \\
\hline Idle ratio $(\%)$ & 22.63 & 17.2 & 12.67 & 22.11 & 29.23 & 9.75 \\
\hline $0 \sim 10 \mathrm{~km} / \mathrm{h}$ & 99 & 145 & 131 & 145 & 92 & 7 \\
\hline Ratio $(\%)$ & 8.39 & 7.72 & 7.28 & 8.06 & 11.79 & 1.75 \\
\hline $10 \sim 20 \mathrm{~km} / \mathrm{h}$ & 116 & 117 & 273 & 263 & 108 & 8 \\
\hline Ratio $(\%)$ & 9.83 & 6.23 & 15.17 & 14.61 & 13.85 & 2 \\
\hline $20 \sim 30 \mathrm{~km} / \mathrm{h}$ & 62 & 180 & 227 & 228 & 56 & 6 \\
\hline Ratio $(\%)$ & 5.25 & 9.58 & 12.61 & 12.67 & 7.18 & 1.5 \\
\hline
\end{tabular}

\begin{tabular}{|l|l|l|l|l|l|l|}
\hline $30 \sim 40 \mathrm{~km} / \mathrm{h}$ & 213 & 321 & 209 & 207 & 204 & 9 \\
\hline Ratio $(\%)$ & 18.05 & 17.09 & 11.61 & 11.5 & 26.15 & 2.25 \\
\hline $40 \sim 50 \mathrm{~km} / \mathrm{h}$ & 172 & 410 & 167 & 174 & 92 & 80 \\
\hline Ratio $(\%)$ & 14.58 & 21.83 & 9.28 & 9.67 & 11.79 & 20 \\
\hline $50 \sim 60 \mathrm{~km} / \mathrm{h}$ & 18 & 156 & 145 & 169 & 0 & 18 \\
\hline Ratio $(\%)$ & 1.53 & 8.31 & 8.06 & 9.39 & 0 & 4.5 \\
\hline $60 \sim 70 \mathrm{~km} / \mathrm{h}$ & 120 & 18 & 64 & 77 & 0 & 120 \\
\hline Ratio $(\%)$ & 10.17 & 0.96 & 3.56 & 4.28 & 0 & 30 \\
\hline $70 \sim 80 \mathrm{~km} / \mathrm{h}$ & 14 & 56 & 66 & 53 & 0 & 14 \\
\hline Ratio $(\%)$ & 1.19 & 2.98 & 3.67 & 2.94 & 0 & 3.5 \\
\hline $80 \sim 90 \mathrm{~km} / \mathrm{h}$ & 16 & 122 & 27 & 25 & 0 & 16 \\
\hline Ratio $(\%)$ & 1.36 & 6.5 & 1.5 & 1.39 & 0 & 4 \\
\hline $90 \sim 100 \mathrm{~km} / \mathrm{h}$ & 46 & 30 & 42 & 25 & 0 & 46 \\
\hline Ratio $(\%)$ & 3.9 & 1.6 & 2.33 & 1.39 & 0 & 11.5 \\
\hline $100 \sim 110 \mathrm{~km} / \mathrm{h}$ & 14 & 0 & 14 & 17 & 0 & 14 \\
\hline Ratio $(\%)$ & 1.19 & 0 & 0.78 & 0.94 & 0 & 3.5 \\
\hline $110 \sim 120 \mathrm{~km} / \mathrm{h}$ & 23 & 0 & 37 & 19 & 0 & 23 \\
\hline Ratio $(\%)$ & 1.95 & 0 & 2.06 & 1.06 & 0 & 5.75 \\
\hline
\end{tabular}

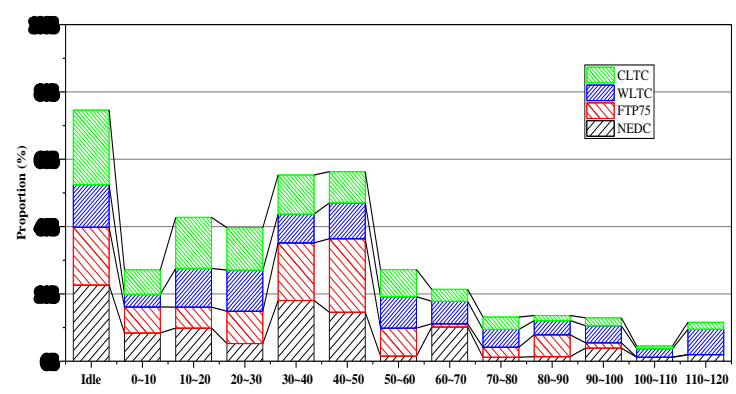

Fig. 7. Speed distribution of typical cycles

\subsection{Comparison of acceleration characteristics}

The comparison of acceleration characteristics of several driving cycles is shown in Table 5 and Figure 8. From the point of view of the maximum acceleration, the maximum acceleration of the transient cycle (such as FTP-75, WLTC, CLTC-P) is larger and relatively close; the maximum acceleration of the modal driving cycle is small. From the point of view of maximum deceleration, CLTC-P is relatively close to other typical driving cycles. From the comparison of average acceleration and deceleration, it is found that the FTP-75 in the United States is higher than other cycles, indicating that the acceleration process is more aggressive; the acceleration of the WLTC is slightly larger than that of the CLTC-P. Analysis of acceleration distribution can draw conclusions similar to the above.

Table 5. Acceleration characteristics of typical cycle

\begin{tabular}{|l|l|l|l|l|l|l|}
\hline & $\begin{array}{l}\text { NED } \\
\text { C }\end{array}$ & $\begin{array}{l}\text { FTP- } \\
75\end{array}$ & $\begin{array}{l}\text { WLT } \\
\text { C }\end{array}$ & $\begin{array}{l}\text { CLTC } \\
-P\end{array}$ & $\begin{array}{l}\text { NED } \\
\text { C1 }\end{array}$ & $\begin{array}{l}\text { NED } \\
\text { C2 }\end{array}$ \\
\hline $\begin{array}{l}\text { Maximum } \\
\text { acceleration }\left(\mathrm{m} / \mathrm{s}^{\wedge} 2\right)\end{array}$ & 1.04 & 1.57 & 1.58 & 1.47 & 1.04 & 0.83 \\
\hline
\end{tabular}




\begin{tabular}{|c|c|c|c|c|c|c|}
\hline \begin{tabular}{|l|} 
Maximum \\
deceleration $\left(\mathrm{m} / \mathrm{s}^{\wedge} 2\right)$
\end{tabular} & -1.39 & -1.57 & -1.49 & -1.47 & -0.99 & -1.39 \\
\hline \begin{tabular}{|l|} 
Average acceleration \\
$\left(\mathrm{m} / \mathrm{s}^{\wedge} 2\right)$
\end{tabular} & 0.53 & 0.62 & 0.53 & 0.45 & 0.64 & 0.36 \\
\hline $\begin{array}{l}\text { Average } \\
\text { deceleration }\left(\mathrm{m} / \mathrm{s}^{\wedge} 2\right)\end{array}$ & -0.75 & -0.71 & -0.58 & -0.49 & -0.71 & -0.88 \\
\hline$<-3.5 \mathrm{~m} / \mathrm{s}^{\wedge} 2$ & 0 & 0 & 0 & 0 & 0 & 0 \\
\hline Ratio (\%) & 0 & 0 & 0 & 0 & 0 & 0 \\
\hline$-3.5 \sim-3 \mathrm{~m} / \mathrm{s}^{\wedge} 2$ & 0 & 0 & 0 & 0 & 0 & 0 \\
\hline Ratio (\%) & 0 & 0 & 0 & 0 & 0 & 0 \\
\hline$-3 \sim-2.5 \mathrm{~m} / \mathrm{s}^{\wedge} 2$ & 0 & 0 & 0 & 0 & 0 & 0 \\
\hline Ratio (\%) & 0 & 0 & 0 & 0 & 0 & 0 \\
\hline$-2.5 \sim-2 \mathrm{~m} / \mathrm{s}^{\wedge} 2$ & 0 & 0 & 0 & 0 & 0 & 0 \\
\hline Ratio (\%) & 0 & 0 & 0 & 0 & 0 & 0 \\
\hline$-2 \sim-1.5 \mathrm{~m} / \mathrm{s}^{\wedge} 2$ & 0 & 10 & 6 & 0 & 0 & 0 \\
\hline Ratio (\%) & 0 & 0.53 & 0.33 & 0 & 0 & 0 \\
\hline$-1.5 \sim-1 \mathrm{~m} / \mathrm{s}^{\wedge} 2$ & 17 & 152 & 43 & 51 & 0 & 17 \\
\hline Ratio (\%) & 1.44 & 8.09 & 2.39 & 2.83 & 0 & 4.25 \\
\hline$-1 \sim-0.5 \mathrm{~m} / \mathrm{s}^{\wedge} 2$ & 144 & 104 & 123 & 122 & 120 & 24 \\
\hline Ratio (\%) & 12.2 & 5.54 & 6.83 & 6.78 & 15.38 & 6 \\
\hline$-0.5 \sim 0 \mathrm{~m} / \mathrm{s}^{\wedge} 2$ & 388 & 636 & 684 & 685 & 262 & 126 \\
\hline Ratio (\%) & 32.88 & 33.84 & 37.97 & 38.03 & 33.59 & 31.5 \\
\hline $0 \sim 0.5 \mathrm{~m} / \mathrm{s}^{\wedge} 2$ & 483 & 695 & 756 & 753 & 269 & 213 \\
\hline Ratio (\%) & 40.93 & 37.03 & 41.97 & 41.81 & 34.49 & 53.25 \\
\hline $0.5 \sim 1 \mathrm{~m} / \mathrm{s}^{\wedge} 2$ & 135 & 161 & 172 & 172 & 116 & 19 \\
\hline Ratio (\%) & 11.44 & 8.57 & 9.56 & 9.56 & 14.87 & 4.75 \\
\hline $1 \sim 1.5 \mathrm{~m} / \mathrm{s}^{\wedge} 2$ & 12 & 108 & 17 & 17 & 12 & 0 \\
\hline Ratio (\%) & 1.02 & 5.75 & 0.94 & 0.94 & 1.54 & 0 \\
\hline $1.5 \sim 2 \mathrm{~m} / \mathrm{s}^{\wedge} 2$ & 0 & 11 & 0 & 0 & 0 & 0 \\
\hline Ratio (\%) & 0 & 0.59 & 0 & 0 & 0 & 0 \\
\hline $2 \sim 2.5 \mathrm{~m} / \mathrm{s}^{\wedge} 2$ & 0 & 0 & 0 & 0 & 0 & 0 \\
\hline Ratio (\%) & 0 & 0 & 0 & 0 & 0 & 0 \\
\hline $2.5 \sim 3 \mathrm{~m} / \mathrm{s}^{\wedge} 2$ & 0 & 0 & 0 & 0 & 0 & 0 \\
\hline Ratio (\%) & 0 & 0 & 0 & 0 & 0 & 0 \\
\hline $3 \sim 3.5 \mathrm{~m} / \mathrm{s}^{\wedge} 2$ & 0 & 0 & 0 & 0 & 0 & 0 \\
\hline Ratio (\%) & 0 & 0 & 0 & 0 & 0 & 0 \\
\hline$>3.5 \mathrm{~m} / \mathrm{s}^{\wedge} 2$ & 0 & 0 & 0 & 0 & 0 & 0 \\
\hline Ratio (\%) & 0 & 0 & 0 & 0 & 0 & 0 \\
\hline
\end{tabular}

\section{Conclusions}

CLTC-P is relatively close to the acquisition data and the acquisition data weighted by GIS, and in the middle, reflecting that CLTC-P is in line with Chinese reality, and is significantly different from other typical cycles. CLTC$P$ is mainly in urban and suburban areas, which has the characteristics of low average speed, high idle ratio and frequent acceleration and deceleration.

\section{References}

1. Wang, Z., Jin, Y., Wang, M., and Wu, W., "New Fuel Consumption Standards for Chinese Passenger Vehicles and their Effects on Reductions of Oil Use and $\mathrm{CO} 2$ Emissions of the Chinese Passenger Vehicle Fleet," Energy Policy 38(9):5242-5250, 2010, doi:10.1016/j.enpol.2010.05.012.

2. Marotta, A., Pavlovic, J., Ciuffo, B., Serra, S. et al., "Gaseous Emissions from Light-Duty Vehicles: Moving from NEDC to the New WLTP Test Procedure," Environmental Science \&Technology 49(14):8315-8322,

2015 , doi:10.1021/acs.est.5b01364.

3. Pelkmans, L. and Debal, P., "Comparison of onRoad Emissions with Emissions Measured on Chassis Dynamometer Test Cycles," Transportation Research Part D:Transport and Environment 11(4):233-241, 2006,doi:10.1016/j.trd.2006.04.001.

4. Huo, H., Yao, Z., He, K., and Yu, X., "Fuel Consumption Rates of Passenger Cars in China: Labels Versus Real-World," Energy Policy 39(11):7130-7135, 2011, doi: 10.1016/j.enpol.2011.08.031.

5. Mock, P., Kuhlwei, J., Tietge, U., Franco, V. et al., "The WLTP: How a New Test Procedure for Cars will Affect Fuel Consumption Values in the EU," International Council on Clean Transportation 9:3547, 2014.

6. Tutuianu, M. Bonnel, P., Ciuffo, B., Haniu, T., lchikawa, N., Marotta, A., Pavlovic, J., and Steven, H. "Development of the World-wide harmonized Light duty Test Cycle (WLTC) and a possible pathway for its introduction in the European legislation,"Transp. Res. Part D Transp. Environ. 40:61-75, 2015, doi: http://dx. doi. orq /10.1016/i. $\operatorname{trd} .2015 .07 .011$

7. United Nations, "Addendum 15: Global technical regulation No. 15 - Worldwide harmonized Light vehicles Test Procedure," Glob. Regist. ECE/TRANS/:1-234, 2014.

8. Weiss, M., Bonnel, P., Hummel, R., Provenza, A., and Manfredi, U., "On-road emissions of light-duty vehicles in Europe," Environ. Sci. Technol. 45(19):8575-8581, 2011, doi:10.1021/es2008424.

Fig. 8. Acceleration distribution of typical driving cycles 